\title{
Superlative More
}

\author{
Penka Stateva \\ Humboldt University, Berlin
}

This paper is concerned with two seemingly unrelated properties of superlatives: (i) their inability to take measure phrases, and (ii) their behavior in elliptical constructions. Both of these properties raise a problem for current semantic theories of superlatives. From a cross-linguistic perspective, I propose a new semantics of superlatives that removes these problems.

\section{Semantic theories of superlatives and measure phrases}

There is an old intuition that the superlative construction is very similar to the comparative construction. Without any loss in the intended meaning, the superlative construction can be replaced by a comparative with a universal quantifier (or a definite plural) in the restrictive clause:

a. The chess set is the most expensive.

b. The chess set is more expensive than every toy.

In a situation where every toy has the same price there is an exact difference between the chess and the toys with respect to "expensiveness". Interestingly, a measure phrase (MP) can be added to the comparative in (2b), but not to the superlative in $(2 \mathrm{a})$ :

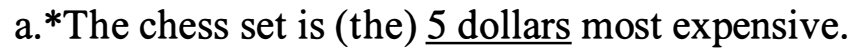

b. The chess set is $\underline{5 \text { dollars }}$ more expensive than every toy.

The contrast in (2) is puzzling from the point of view of existing theories of superlatives. This is so because irrespective of the differences between them, they are all direct extensions of theories of comparatives. Let us illustrate that and see how the problem arises.

To start with, I will briefly review how measure phrases enter the semantic computation in the comparative construction and then I will consider their potential presence in the superlative construction. Assuming Kennedy's (1999) framework, a sentence like (3) is predicted to be true when the relation greater than holds between a "reference value" and the "standard value".

(3) The chess set is more expensive than the Barbie doll.

In (3) the reference value is related to the referent of the DP in the main clause. This is the degree that corresponds to the chess set on the scale introduced by the predicate expensive. The standard value is related to the DP in the than-clause. 
That is the degree that corresponds to the Barbie doll on the same scale. In general, the relation between the reference and the standard value is provided by the degree word -er/less, which has the lexical entry in (4): ${ }^{1}$

$$
\begin{aligned}
& {[[-e r]]:=\lambda G: G \in D_{<e, d>}[\lambda y: y \in D \cdot[\lambda x: x \in D \cdot G(x)>G(y)]]} \\
& {[[\text { less }]]:=\lambda G: G \in D{ }_{<e, d>} \cdot[\lambda y: y \in D \cdot[\lambda x: x \in D \cdot G(x)<G(y)]]}
\end{aligned}
$$

The denotation of the degree word is applied first to the denotation of a gradable predicate, $G$ in (4). In this approach, such predicates express measure functions: they map an individual to a degree from a contextually specified scale. The thanclause, which in phrasal comparatives like (3) denotes an individual, is the second argument of the comparative word. Applying $G$ to that individual gives the standard value. Applying $G$ to the compared individual from the main clause gives the reference value. That individual is the most external argument of er/less. To illustrate the compositional interpretation of (3) consider (5):

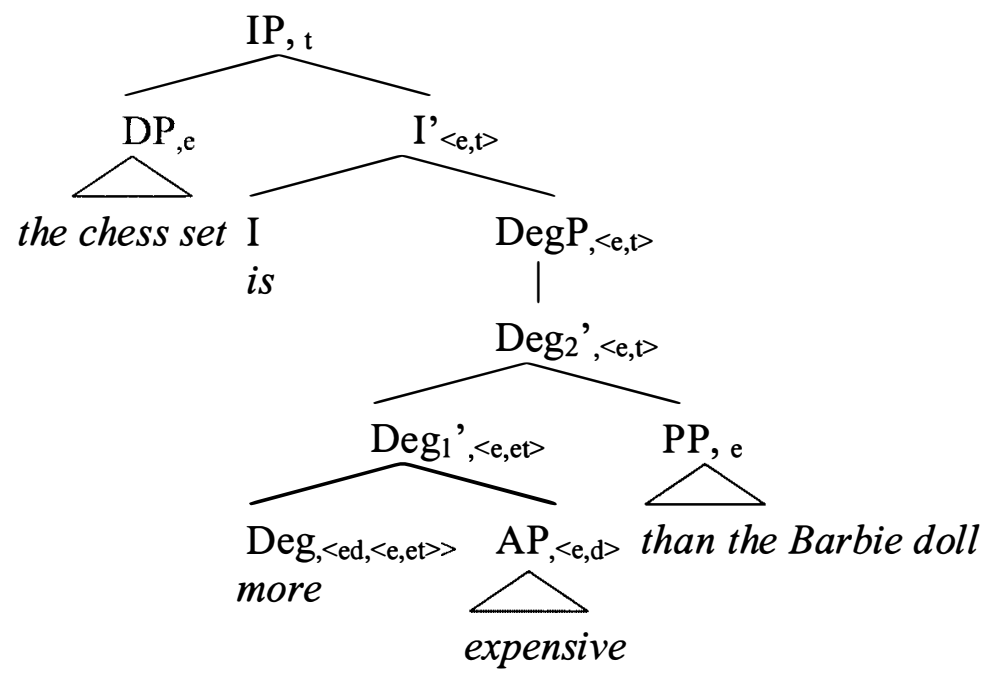

$[[\mathrm{AP}]] \quad=\lambda \mathrm{z}: \mathrm{z} \in \mathrm{D}$.expensive $(\mathrm{z})$

$[[\mathrm{Deg}]]=\lambda \mathrm{G}: \mathrm{G} \in \mathrm{D}_{<\mathrm{e}, \mathrm{d}>} \cdot[\lambda \mathrm{y}: \mathrm{y} \in \mathrm{D} \cdot[\lambda \mathrm{x} \cdot \mathrm{x} \in \mathrm{D} \cdot \mathrm{G}(\mathrm{x})>\mathrm{G}(\mathrm{y})]]$

$\left[\left[\right.\right.$ Deg' $\left.\left._{1}\right]\right]=\lambda \mathrm{y}: \mathrm{y} \in \mathrm{D} \cdot[\lambda \mathrm{x}: \mathrm{x} \in \mathrm{D} \cdot \operatorname{expensive}(\mathrm{x})>\operatorname{expensive}(\mathrm{y})]$

$[[\mathrm{PP}]]=$ the Barbie doll

$\left[\left[\right.\right.$ Deg' $\left.\left._{2}\right]\right]=[[\mathrm{DegP}]]=\lambda \mathrm{x}: \mathrm{x} \in \mathrm{D}$.tall $(\mathrm{x})>$ expensive $($ the Barbie doll $)$

[[IP]] = 1 iff expensive(the chesss set) $>$ expensive(the Barbie doll)

[[The chess set is more expensive than the Barbie doll]] $=1$ iff

the degree, associated with the chess set on the "expensive" scale is greater than the degree associated with the Barbie doll on the same scale.

Let us now turn to comparative constructions containing measure phrases. Consider (6). It is predicted to be true when the reference value equals the sum of the standard value and the measure phrase.

(6) The chess set is 5 dollars more expensive than the Barbie doll. 
Within the "adjective-as-a-measure-function" approach, it is assumed that the extended adjectival projection has a syntactic structure within the lines of Abney (1987). In it [Spec, DegP] is the standard position hosting measure phrases, as in (7).

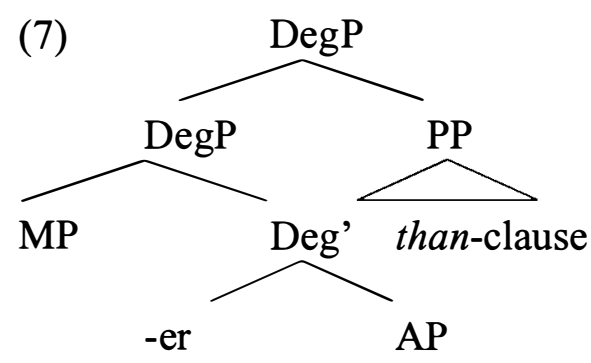

The lexical entry for -er/less used in (6) involves then one more ingredient: the denotation of MP:
a. $[[-e r]]:=\lambda \mathrm{G}: \mathrm{G} \in \mathrm{D}_{<\mathrm{e}, \mathrm{d}>} \cdot\left[\lambda \mathrm{d}: \mathrm{d} \in \mathrm{D}_{\mathrm{d} \cdot} \cdot[\lambda \mathrm{y}: \mathrm{y} \in \mathrm{D} \cdot[\lambda \mathrm{x}: \mathrm{x} \in \mathrm{D} \cdot \mathrm{G}(\mathrm{x})=\mathrm{d}+\mathrm{G}(\mathrm{y})]]\right]$
b. [[less]] := $=\lambda \mathrm{G}: G \in \mathrm{D}_{<\mathrm{e}, \mathrm{d}>} .\left[\lambda \mathrm{d}: \mathrm{d} \in \mathrm{D}_{\mathrm{d} \cdot}[\lambda \mathrm{y}: \mathrm{y} \in \mathrm{D} \cdot[\lambda \mathrm{x}: \mathrm{x} \in \mathrm{D} \cdot \mathrm{G}(\mathrm{x})+\mathrm{d}=\mathrm{G}(\mathrm{y})]]\right]$

Using (8), we arrive at intuitively correct truth conditions for (9):

[[The chess set is 5 dollars more expensive than the Barbie doll]] $=1$ iff the degree, measured in dollars, associated with the chess set on the "expensive" scale equals the sum of 6 dollars and the degree associated with the Barbie doll on the same scale.

What comes as a surprise, however, is the fact that extending Kennedy's view on comparison to the superlative construction, as Farkas and Kiss (2000) have done, leads to predicting a well-formed interpretation for (2a) parallel to (9), given an appropriate context in which the difference in price between the chess set and any other toy is exactly 5 dollars. But in English, as in many other languages, sentences like (2a) are not acceptable. To highlight the problem, let us see in more detail where the theory stumbles. Farkas and Kiss assign the same status to -est as Kennedy to -er: -est provides the relation greater than that holds between a reference and a standard value:

$$
\begin{aligned}
& \text { a.[[est]]: }=\lambda G: G \in D_{<e, d>} \cdot\left[\lambda P: P \in D_{<e, t>\cdot}[\lambda x: x \in D . G(x)>\max (\lambda d . \exists z \neq x[z \in P\right. \\
& \quad \& d=G(z)])]] \\
& \text { b. }[[\text { least }]]:=\lambda G: G \in D_{<e, d>\cdot[}\left[\lambda P: P \in D_{<e, t>}[\lambda x: x \in D . G(x)>\right. \\
& \quad \max (\lambda d . \exists z \neq x[z \in P \& d=G(z)])]],
\end{aligned}
$$

where $\mathrm{G}$ is a gradable adjective, $\mathrm{P}$ is a comparison set containing individuals and

$\max :=\lambda \mathrm{P} \in \mathrm{D}_{<\mathrm{d}, \triangleright>} .[[$ the $\left.]]\left(\lambda \mathrm{d} . \mathrm{P}(\mathrm{d}) \& \forall \mathrm{d}_{1}\left[\mathrm{P}\left(\mathrm{d}_{1}\right) \rightarrow \mathrm{d}_{1} \leq \mathrm{d}\right]\right]\right)$ 
$\mathrm{G}(\mathrm{x})$ corresponds to the standard value and $\max (\lambda \mathrm{d} . \exists \mathrm{z} \neq \mathrm{x}[\mathrm{z} \in \mathrm{P} \& \mathrm{~d}=\mathrm{G}(\mathrm{z})])$ to the reference value. Under these assumptions, (1), for example will have the logical form and interpretation in $(11):^{2}$

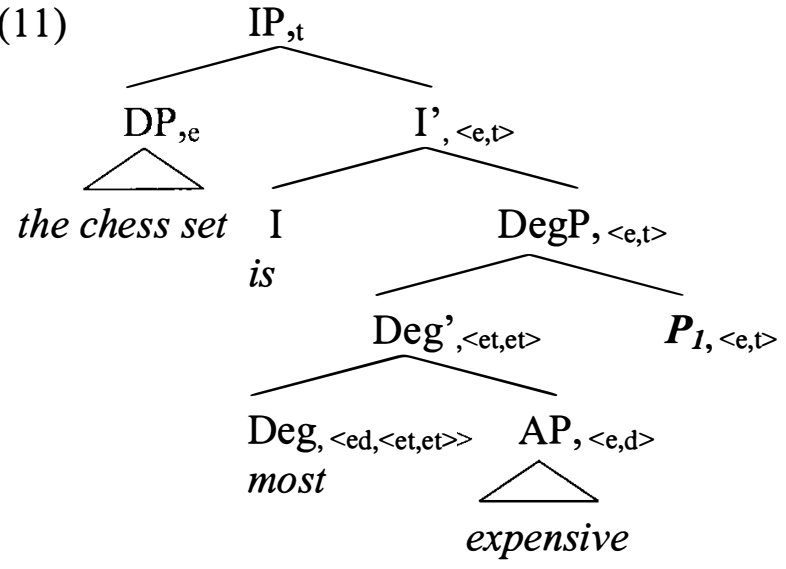

$[[\mathrm{AP}]]=\lambda \mathrm{z}: \mathrm{z} \in \mathrm{D}$.expensive $(\mathrm{z})$

$[[D e g]]=\lambda \mathrm{G}: G \in D_{<e, d>}\left[\lambda P: P \in D_{<e, \downarrow} \cdot[\lambda x: x \in D \cdot G(x)>\right.$ $\max (\lambda \mathrm{d} . \exists \mathrm{y} \neq \mathrm{x}[\mathrm{y} \in \mathrm{P} \& \mathrm{~d}=\mathrm{G}(\mathrm{y})])]]$

$\left[\left[\right.\right.$ Deg' $\left.\left.^{\prime}\right]\right]=\lambda \mathrm{P}: \mathrm{P} \in \mathrm{D}_{<\mathrm{e}, \mathrm{t}>} .[\lambda \mathrm{x}: \mathrm{x} \in \mathrm{D}$.expensive $(\mathrm{x})>\max (\lambda \mathrm{d} . \exists \mathrm{y} \neq \mathrm{x}[\mathrm{y} \in \mathrm{P} \&$ $\mathrm{d}=\operatorname{expensive}(\mathrm{y})])]$

$[[\operatorname{DegP}]]=\lambda \mathrm{x}: \mathrm{x} \in \mathrm{D}$.expensive $(\mathrm{x})>\max \left(\lambda \mathrm{d} . \exists \mathrm{y} \neq \mathrm{x}\left[\mathrm{y} \in \mathrm{P}_{1} \& \mathrm{~d}=\operatorname{expensive}(\mathrm{y})\right]\right)$

$[[\mathrm{IP}]]=1$ iff expensive(the chess $\operatorname{set})>\max \left(\lambda \mathrm{d} . \exists \mathrm{y} \neq \mathrm{x}\left[\mathrm{y} \in \mathrm{P}_{1} \& \mathrm{~d}=\operatorname{expensive}(\mathrm{y})\right]\right)$

$\mathrm{P}_{1}=\{\mathrm{x}: \mathrm{x}$ is a (relevant) toy $\}$

[[The chess set is the most expensive]] $=1$ iff the degree, associated with the chess set on the "expensive" scale is greater than the biggest degree associated with any other compared toy on the same scale.

That interpretation corresponds to speakers' intuitions. However, nothing in the syntactic or semantic assumptions considered so far, prevents us from assigning the interpretation in (12) to (2a) if in analogy to the comparative construction, the contribution of the MP is taken into consideration:

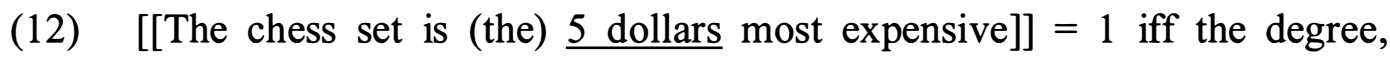
associated with the chess set on the "expensive" scale equals the sum of 5 dollars and the biggest degree associated with any other compared toy on the same scale.

(12) follows on the assumption that the reference value equals the sum of the standard value and the degree denoted by the measure phrase in both comparison constructions. Therefore, I conclude that measure phrases present a challenge to current theories of superlatives. Note that alternative theories of superlatives (cf. Gawron (1995), Heim (1999), Heim (2000), Sharvit and Stateva (2002)) face the 
same problem given that they too are direct extensions of corresponding theories of comparatives. And as we saw, the root of the problem lies in the parallel treatment of-er/less and-est/least.

\section{So-pronominalization}

Equally mysterious is a contrast between the comparative and the superlative construction in their ability to license the surface anaphor so. Corver (1997) observes that (i) so stands for an AP, and (ii) so is acceptable in the comparative construction. This is shown in (13):

a. John is fond of Mary. Bill seems more so.

b. The police searched the big room carefully, but the small room less so.

Given the current unified theories of comparison, one would expect sopronominalization to be possible also in the superlative construction. However, the expectation is not borne out. Consider the data below:

(14) a. *John and Scott are fond of Mary. Bill seems the most so.

b. John and Scott are fond of Mary. Bill seems the most fond of her.

c. cf. (13a)

(15) a. *John and Scott are really industrious. But Bill is the most so.

b. John and Scott are really industrious. But Bill is the most industrious.

c. cf. John is really industrious. But Bill is more so.

(16) a. *John was fond of mathematics in high school and in college, and he seems most so now that he entered a graduate program.

b. John was fond of mathematics in high school and in college, and he seems most fond of mathematics now that he entered a graduate program.

c. cf. John was fond of mathematics in high school and he seems more so now that he entered a graduate program.

(17) a. ${ }^{*}$ The police searched the kitchen and the living-room very carefully but the bedroom the least $s$.

b. The police searched the kitchen and the living-room very carefully but the bedroom the least carefully.

c. cf. The police searched the living-room very carefully but the bedroom less $s o$.

(18) a. *The story is interesting, perhaps the most so from what we heard tonight.

b. The story is interesting, perhaps the most interesting from what we heard tonight.

c. cf. The story is interesting, more so than what we heard tonight. 
The contrast in the acceptability between the (c) sentences and the (a) sentences above is very robust. In each of the (b) examples, the superlative expression is felicitous, so what makes the (a) examples bad must be some violation of the condition for licensing $s o$ in superlatives.

\section{Proposal: Superlative more}

I aim to account for these differences between the two comparison constructions by proposing a new semantic analysis of the superlative construction. In a nutshell, the proposal is that universally, the head of the superlative DegP is not the superlative degree word but rather a comparative 'operator' which in languages such as English is phonologically null. In other words, I postulate a superlative more. The superlative degree word functions as a standard of measurement (than-clause) filling the syntactic position of MPs. I give independent evidence for the proposal in Section 3.2. Section 4 explains why the "puzzles" with measure phrases and so-pronominalization in the superlative are predicted under the new proposal. I Section 5, I explore some consequences of the proposal. Section 6 summarizes the conclusions.

\subsection{Technical implementation}

I observed in the first section that it is impossible to get measure phrases in the [Spec, DegP] position, "canonical" for the comparison constructions. The relevant example (2a) is repeated as (19):

${ }^{*}$ The chess set is (the) 5 dollars most expensive.

In the comparative construction, there is an option of introducing an MP by a byphrase like (20), or example:

(20) The chess set is more expensive than the Barbie doll by 5 dollars.

Is such a by-phrase possible with the superlative? The answer is not straightforward. (21a) is found perfectly normal by all of my informants. ${ }^{3}(21 \mathrm{~b})$ is at best marginal, and the judgment on (21c) varies to fully unacceptable by some informants:

(21) a. The chess set is the most expensive by far.

b. ?/?? The chess set is the most expensive by at least/ at most five dollars.

c. $\left(^{*}\right)$ The chess set is the most expensive by five dollars.

My informants, however, all agree that the more vague the measure phrase, the greater the degree of acceptability with the superlative. ${ }^{4}$ These data prompt the conclusion that the measure phrase is not, after all, incompatible semantically 
with the superlative construction. On the one hand, the variability in the judgments of (21) points to a possible pragmatic factor that comes into play. On the other hand, the fact that both exact and vague measure phrases, as in (22), are impossible in the pre-adjectival position suggests that that syntactic position is unavailable if in principle there are no semantic reasons precluding the measure phrase from appearing there.

a. ${ }^{*}$ The chess set is (the) at least/ at most 5 dollars most expensive. b. *The chess set is (the) far most expensive.

If we are correct in concluding that the syntactic position of the measure phrase is unavailable in the superlative construction, then that must be the default syntactic position for some other element. The most plausible candidate is -est itself. In other words, -est and MPs have the same syntactic distribution. The following observation, due to Martin Hackl (p.c.), supports this conclusion. Sopronominalization is impossible not only with the superlative, as we saw in the previous section but also with the comparative if there is a MP in the latter:
a. ${ }^{*} \mathrm{John}$ is tall but Bill is $10 \mathrm{~cm}$ more so.
b. cf. John is tall but Bill is more so.

With this in mind I propose the syntactic structure of the superlative construction in (24):

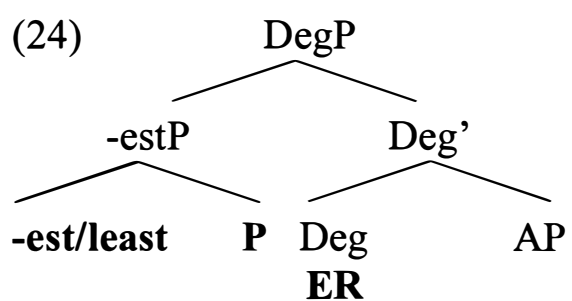

It seems intuitively correct to propose that the head of the superlative construction is a comparative degree word. In English this is a null morpheme, call it ER. The intuition rests on the fact that in both the superlative and the comparative construction the degree relation, which by standard assumption is provided by the head, is the same: greater /smaller than. In the comparative construction this relation holds between a reference value and a standard value which comes (in)directly from the than-clause. What seems to be missing in the superlative construction is the standard value (or a than-clause). The proposal is then that est/least and the variable associated with the comparison set form a constituent which functions semantically as a than-clause to yield together the standard value and have the structural position of a measure phrase in other comparison constructions: it is a specifier of DegP. ${ }^{5,6}$

Let us now implement these assumptions in a proposal about the semantics of the superlative construction. Contrary to common assumptions about the superlative but in line with the tradition on the semantics of the comparative, I 
place the locus of difference between negative and positive superlative not in -est and least but in the head of the construction. Therefore we have two lexical entries for $E R$. (25) specifies the meaning of $E R_{1}$ and $E R_{2} . E R_{1}$ heads the positive superlative construction (the most beautiful), while $\mathrm{ER}_{2}$ heads the negative superlative construction (the least beautiful). Note that these are the entries that a Kennedy-type framework assigns to the comparative degree word in sentences like 'The chess set is more expensive than 5 dollars'.

$$
\begin{aligned}
& \text { a. }\left[\left[E_{1}\right]\right]:=\lambda \mathrm{G}: G \in D_{<\mathrm{e}, \mathrm{d}>\cdot}\left[\lambda \mathrm{d}: \mathrm{d} \in \mathrm{D}_{\mathrm{d} \cdot}\left[\lambda \mathrm{x}: \underline{\mathrm{d}}_{1}\left[\mathrm{G}(\mathrm{x})=\mathrm{d}_{1}\right] \cdot \mathrm{G}(\mathrm{x})>\mathrm{d}\right]\right] \\
& \text { b. }\left[\left[\mathrm{ER}_{2}\right]\right]:=\lambda \mathrm{G}: G \in \mathrm{D}_{<\mathrm{e}, \mathrm{d}>\cdot}\left[\lambda \mathrm{d}: \mathrm{d} \in \mathrm{D}_{\mathrm{d} \cdot} \cdot\left[\lambda \mathrm{x}: \underline{\mathrm{d}}_{1}\left[\mathrm{G}(\mathrm{x})=\mathrm{d}_{1}\right] . \mathrm{G}(\mathrm{x})<\mathrm{d}\right]\right]
\end{aligned}
$$

The null degree head in the superlative DegP provides the comparison relation. (25) says that $E R$ applies to an adjective denotation $G$ first, then to a degree $d$, which is the standard value, and finally to an individual $x$ to yield True just in case the reference value $G(x)$ is greater than the standard value $d$. As usual, we assume that the superlative construction comes with a presupposition that there is some degree on the scale associated with the gradable adjective $G$ that corresponds to the external argument $x$ of the comparison head. This presupposition condition is now part of the semantics of $E R$ and corresponds to the underlined part of its lexical entry.

-Est/least applies to the variable that denotes the comparison set and together they supply the standard value. ${ }^{7}$ Its lexical entry is given in (26): ${ }^{8}$

$$
\left[\left[- \text { est } / \text { least }_{\mathrm{B}}\right]\right]^{\mathrm{g}}:=\lambda \mathrm{P}: \mathrm{P} \in \mathrm{D}_{<\mathrm{e}, \mathrm{t}>} \cdot \max (\lambda \mathrm{d} \cdot \exists \mathrm{y}[\mathrm{y} \in \mathrm{P} \& \mathrm{~d}=\mathrm{g}(\mathrm{B})(\mathrm{y})])
$$

-Est/Least apply to the denotation of the comparison set to yield a degree. That degree is the maximum of the set of degrees $d$ such that $d$ corresponds to some individual from the comparison set on the scale associated with the relevant gradable adjective. But how do we know which is the relevant gradable adjective? The idea is that -est/least contains an anaphoric element, an index which corresponds to a variable of the type of gradable adjectives $<\mathrm{e}, \mathrm{d}>$. Its value is contextually fixed. Consider again, for example, (27):

The chess set is the most expensive.

Mentioning the measure function expensive in the context of utterance of (27), makes the $<\mathrm{e}, \mathrm{d}>$-function $\lambda x$.expensive $(x)$ appropriate as a value of the index of most. Let us illustrate the proposal with the sample calculation of the interpretation of (27). Its LF and the denotation at each node are given in (28a) and $(28 b)$ : 
(28)

a.

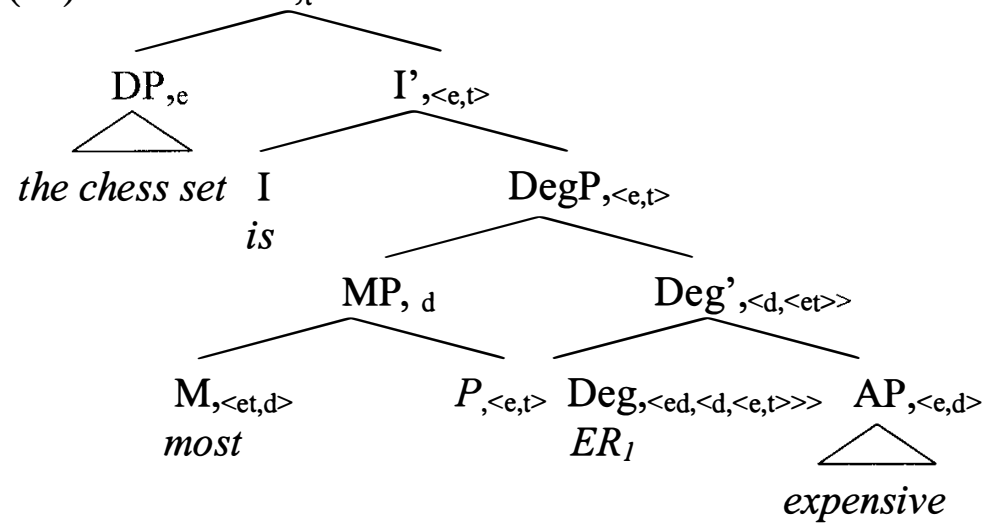

b. $[[\mathrm{AP}]]=\lambda \mathrm{x}$.expensive $(\mathrm{x})$

$[[D e g]]=\lambda \mathrm{G}: G \in D_{<e, d>} .\left[\lambda \mathrm{d}: \mathrm{d} \in \mathrm{D}_{\mathrm{d} \cdot} \cdot[\lambda \mathrm{x}: \mathrm{x} \in \mathrm{D} . \mathrm{G}(\mathrm{x})>\mathrm{d}]\right]$

$\left[\left[\right.\right.$ Deg' $\left.\left.^{\prime}\right]\right]=\lambda \mathrm{d}: \mathrm{d} \in \mathrm{D}_{\mathrm{d}} \cdot[\lambda \mathrm{y}: \mathrm{y} \in \mathrm{D}$.expensive $(\mathrm{y})>\mathrm{d}]$

$\left[\left[\operatorname{most}_{1}\right]\right]^{\mathrm{g}}=\lambda \mathrm{P}: \mathrm{P} \in \mathrm{D}_{<\mathrm{e}, \mathrm{\downarrow}>} \cdot \max (\lambda \mathrm{d} \cdot \exists \mathrm{z}[\mathrm{z} \in \mathrm{P} \& \mathrm{~d}=\mathrm{g}(1)(\mathrm{z})])$

$[[\mathrm{MP}]] \quad=\max (\lambda \mathrm{d} . \exists \mathrm{z}[\mathrm{z} \in \mathrm{P} \& \mathrm{~d}=$ expensive $(\mathrm{z})])$

$[[$ DegP $]]=\lambda \mathrm{y}: \mathrm{y} \in \mathrm{D}$.expensive $(\mathrm{y})>\max (\lambda \mathrm{d} . \exists \mathrm{z}[\mathrm{z} \in \mathrm{P} \& \mathrm{~d}=$ expensive $(\mathrm{z})])$

$[[$ The chess set is the most expensive $]]=1$ iff

expensive(the chess set $)>\max (\lambda \mathrm{d} . \exists \mathrm{z}[\mathrm{z} \in \mathrm{P} \& \mathrm{~d}=$ expensive $(\mathrm{z})])$

$\mathrm{g}(1)=\lambda \mathrm{x} \cdot \operatorname{expensive}(\mathrm{x})$

$\mathrm{P}=\{\mathrm{x}: \mathrm{x}$ is a (relevant) toy $\neq$ the chess set $\}$

\subsection{Independent evidence}

\subsubsection{Most and more in the superlative}

An independent piece of evidence motivating the proposal comes from new data from Slavic and Baltic languages: Old Bulgarian, Russian, Serbo-Croatian and Latvian. The superlative construction in each of these languages requires both a superlative and a comparative degree word. Consider first the Serbo-Croatian data in $(29)-(31)$ :

a. Ivan je najpametniji

Ivan is most-smart-er

'Ivan is the smartest.'

b. *Ivan je najpametan

Ivan is most-smart

(30) Ivan se ponašao
Ivan behaved

Ivan behaved most wisely (compared to everyone else).' 
b. *Ivan se ponašao najpametno

Ivan behaved most-wisely

(31)

a. Ivan je pametniji od Milene

Ivan is smart-er than Milena

'Ivan is smarter than Milena.'

b. Ivan se ponašao pametnije od Milene

Ivan behaved wisely-er than Milena

'Ivan behaved more wisely than Milena.'

The superlative form of gradable adjectives and gradable adverbs in Serbo-Croatian is formed by adding naj (the superlative particle) to the comparative form, as in (29a) and (30a). Prefixing naj to the absolute form is ungrammatical as (29b) and (30b) show. (31) illustrates the comparative construction. These data would be a mystery under any other current theory of superlatives. But under the proposal madehere, this is not so. The head of the superlative phrase would be the comparative degree word, while the superlative particle is its specifier.

Let us also discuss some data from Russian. ${ }^{9}$ In all relevant respects it is very similar to the Serbo-Croatian examples above. The major difference is that unlike Serbo-Croatian, Russian has a construction in which the comparative markers are phonologically independent. As expected, the word order here reflects the hierarchical relations between elements in DegP argued for in the previous section. Consider (32) and (33), which illustrate the superlative construction with adverbs and with adjectives:

a. Ivan skonstruiroval dvigatel' naibolee effektivno Ivan designed engine most-more effectively 'Ivan designed an engine the most effectively.'

b. Oleg skonstruiroval dvigatel' naimenee effektivno Oleg designed engine most-less effectively

'Oleg designed an engine the least effectively.'

c. *Ivan skonstruiroval dvigatel' naieffektivno Ivan designed engine most-effectively

a. Ivan naibolee vydajuščijsja učenyj Ivan most-more outstanding scholar 'Ivan is the most outstanding scholar,'

b. Oleg naimenee vydajuščijsja učenyj Oleg most-less outstanding scholar 'Oleg is the least outstanding scholar.' 


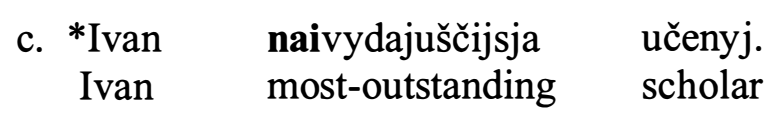

Judging by the contrast between the (a) and (b) examples on the one hand, and the (c) examples, on the other, it becomes clear that the construction requires both the superlative particle nai and bolee/ menee which are the forms of the comparative degree words used in the analytical comparative construction, illustrated in (34) and (35):

a. Ivan skonstruiroval dvigatel' bolee effektivno čem Oleg Ivan designed engine more effectively than Oleg 'Ivan designed an engine more effectively than Oleg.'

b. Oleg skonstruiroval dvigatel' menee effektivno čem Ivan Olegdesigned engine less effectively than Ivan 'Oleg designed an engine less effectively than Ivan.'
a. Ivan bolee vydajuščijsja učenyj čem Oleg Ivan more outstanding scholar than Oleg 'Ivan is a more outstandig scholar than Oleg.'
b. Oleg menee vydajuščijsja učenyj čem Ivan Oleg less outstanding scholar than Ivan 'Oleg is a less outstanding scholar than Ivan.'

There are two conceivable ways of accommodating Slavic-type languages into a semantic theory of superlatives. The first one is to assume that the presence of the comparative degree word has no effect on the meaning of the construction. But then we will be missing a generalization that whenever a superlative DegP requires a semantically vacuous Deg head, then that head always happens to be a comparative degree word. The second is to revise the view about the semantics of the superlative element (nai-) and use the contribution of the comparative operator. The semantics for -est/least that I developed has an advantage over the other proposals since that it is the only proposal which can accommodate the Slavic data. If the proposal is on the right track, a more general conclusion emerges: crosslinguistically, there are two options for realizing the head of the superlative construction - English-type languages use a null counterpart of the comparative degree word, while Slavic-type languages use an overt comparative word in the superlative construction. ${ }^{10}$

\subsubsection{The context-dependency of-est/least}

Russian has another, more productive pattern of forming a superlative construction. It is illustrated in (36): 
Maša kupila samyj dorogoj učebnik Maša bought most expensive textbook 'Maša bought the most expensive textbook.'

This construction makes use of an anaphorical element, which serves as a superlative marker. The root of samyj, which means most is the root of the Russian word for same/ identical, as we can see from (37).
Maša kupila tot že samyj učebnik
Maša bought that same/identical textbook
'Maša bought that same/very textbook.'

The fact that same is an anaphoric element suggests that most could be, too.

\section{Back to the original problems}

We started this discussion with an observation about two discrepancies between the comparative and the superlative construction. The first one regards measure phrases. Under this proposal the contrast in the distribution of MPs is no longer a mystery: the [Spec, DegP] position which accommodates an MP is never free in the superlative construction (cf. 2a), but available in principle in the comparative (cf.2b).

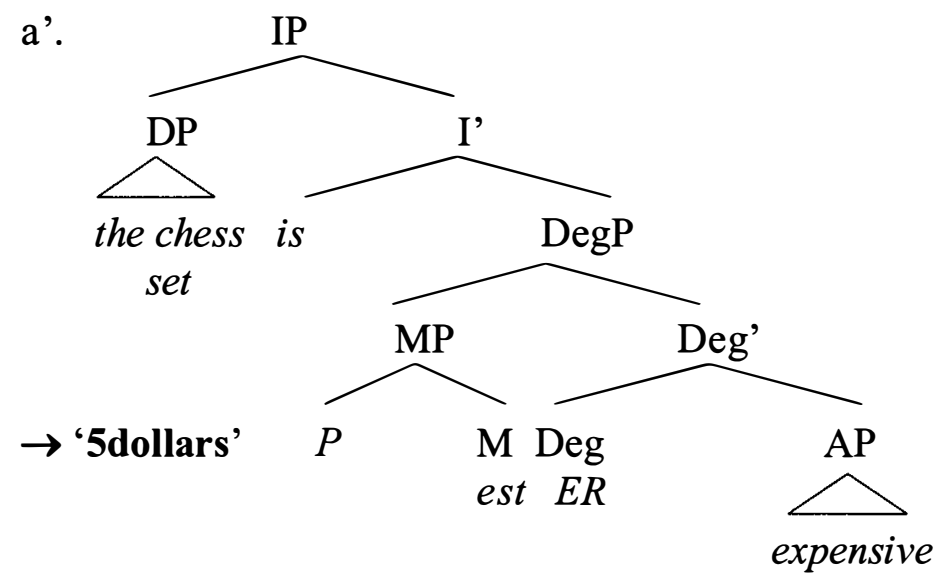

Recall also that I argued that semantically the constituent formed by -est and $P$ functions as a than-clause of the sort which directly provides a degree as a standard value for the degree relation. In other words, (38a) is similar to (38b) with respect to the kind of than-clause involved in them:

a. The chess set is the most expensive.

b. The chess set is more expensive than 15 dollars.

It is not surprising then that adding a by-phrase with a measure phrase to any of them is equally not well accepted: 
a. $\left({ }^{*}\right)$ The chess set is the most expensive by 5 dollars.

b. $\left(^{*}\right)$ The chess set is more expensive than 15 dollars by 5 dollars.

Let us now turn to the problem with so-pronominalization. Recall that it is possible with the comparative construction but not with the superlative. This contrast also follows from the proposal developed here. Consider again (23) repeated here as $(40 \mathrm{~b})$ and $(40 \mathrm{c})$ :
a. ${ }^{*}$ John and Sue are tall but Bill is the most so.
b. *John is tall but Bill is $10 \mathrm{~cm}$ more so.
c. cf. John is tall but Bill is more so.

It is a very curious fact that even in the comparative, which in principle allows so-pronominalization, that process becomes impossible when a MP is present in the DegP with an elided part. Whatever conditions for licensing this particular kind of ellipsis with so in (40b) are violated, they must be violated in (40a) too if it is correct that the MP position there is filled by most.

\section{Empirical consequences}

The proposal advanced here can be verified by studying other types of ellipsis in addition to so-pronominalization. We argued that among the languages which have the superlative construction there are two types: one using a null comparative morpheme as a head of the superlative construction, and a second which uses an overt comparative morpheme. Null heads are subject to certain interface conditions. For example, Ormazabal (1995) argues that all null heads have affix-like properties and they need a phonological host. For our purposes, this implies that $E R$ and affixal overt comparative heads like-er are subject to the same conditions, while more, less, the Russian bolee and other non-affixal heads are not. Consider again so-pronominalization with the comparative in English. Recall that $-e r$, which is an affix, has a phonologically independent allomorph more. -er needs an adjectival host. Its phonological requirements are met in (41).

John is taller than Bill is.

However, these requirements are not met in (42a). So cannot serve as a phonological host for -er. But since more has the same syntactic and semantic properties as -er, and crucially it is not an affix, more can be used in the sopronominalization construction. Moreover, more is used even in cases in which so stands for an adjective, like tall, that otherwise forms a comparative with -er in the non-elliptical construction, as shown in (42b):
a. $\quad *$ Bill is tall. But John is even so-er.
b. Bill is tall. But John is even more so. 
The new account makes a prediction: in languages, in which the head of the superlative construction is not an affix, various ellipsis phenomena should be possible with superlatives. ${ }^{11}$ The prediction is borne out. Željko Bošković (p.c.) provides an example from Serbo-Croatian:

$\begin{array}{llll}\text { ?Ivan je najmanje } & \text { pametan, a Petar je najviše } \\ \text { Ivan is } & \text { most-less } & \text { smart but Peter is } & \text { most-more }\end{array}$

'John is the least smart but Peter is the most smart.'

\section{Conclusion}

To summarize, in light of the differences between the comparative and the superlative degree constructions with respect to their abilities to take measure phrases and to license ellipsis, I propose a new semantics for superlatives. The paper highlights unnoticed so far cross-linguistic differences in the superlative construction which also find an explanation with the proposal developed here.

\section{Endnotes}

*An earlier draft of this paper appears as part of my 2002 University of Connecticut doctoral dissertation. For extremely valuable comments and discussion of the material and the data presented here I am indebted to the members of my dissertation committee Yael Sharvit, Željko Bošković, Sigrid Beck, Howard Lasnik and Roger Schwarzschild and also to Klaus Abels, Doug Saddy, Arthur Stepanov, Saša Vukić. I am also grateful for comments from the audience of SALT 13, particularly to David Beaver, Martin Hackl, Chris Kennedy and Manfred Krifka.

1 I am only discussing the phrasal comparative here in order to keep the discussion simpler and clearer. Clausal comparatives would involve slightly different assumptions but the point that we are making on the basis of the "simpler" case of phrasal comparative stays: a unified treatment of comparatives and superlatives does not predict the unacceptability of measure phrases in the superlative construction.

${ }^{2}$ I assume for simplicity that the definite article is vacuous in this construction.

${ }^{3}$ The example was suggested to me by Manfred Krifka.

${ }^{4}$ It is interesting to note that the exact opposite of this tendency holds with the comparative (Chris Kennedy, p.c.). The vaguer the MP in the by-phrase is, the less acceptable it becomes:

(i) a. $(*)$ The chess set is more expensive by far.

b. ? The chess set is more expensive by at least/ at most five dollars.

c. The chess set is more expensive by five dollars. 
${ }^{5}$ Thanks to Roger Schwarzschild for helping me figure that out.

6 It remains to be explored what the syntactic motivation is for this "unusual" structural position of the than-clause in the superlative construction which is treated as a special comparative.

${ }^{7}$ Note that the comparison class must exclude the individual which is the external argument of the head ER. For space reasons, I am not going to provide arguments here for this shift from other semantic theories of superlatives like Heim (1999), Stateva (2000), Sharvit and Stateva (2002), etc. The reader is referred to Stateva (2002) for such arguments.

${ }^{8}$ If -est and least have the same semantics one would like to know why they have different phonological features. I suggest that this is a result of agreement between -est and least with $E R_{1}$ and $E R_{2}$, respectively. Other languages, as discussed in Section 4, do not differentiate between negative and positive superlative markers. Rather they use different comparative heads to signal the type of the superlative construction.

9 The pattern discussed here is not fully productive. Russian has also another strategy of forming the superlative which will be discussed further in this section.

${ }^{10}$ It would be interesting to study the acquisition of the superlative construction with respect to this proposal. If the difference between English and Slavic is parametrized, all else equal, we would expect children to make mistakes before they learn which pattern their language belongs to. Most significant would be mistakes like *most taller for English speaking children, and *najmudro 'most wisely' for children acquiring Serbo-Croatian, for example. Thanks to Y. Sharvit for suggesting that.

11 This prediction holds if there are no independent ellipsis licensing conditions (such as the requirement that [Spec, DegP] must not be filled in the case with sopronominalization; see Section 4) that could rule the construction out.

\section{References}

Abney, Steven. 1987. The English noun phrase in its sentential aspect. Doctoral dissertation, MIT, Cambridge, Mass.

Corver, Norbert. 1997. Much-support as a Last Resort. Linguistic Inquiry 28: 119164.

Farkas, Donka F., and Katalin E. Kiss. 2000. On the comparative and absolute readings of superlatives. Natural Language and Linguistic Theory 18: 415-455.

Gawron, J.M. 1995. Comparatives, Superlatives and Resolution. Linguistics and Philosophy 18: 333-380.

Heim, Irene. 1999. Notes on superlatives. Ms., MIT, Cambridge.

Heim, Irene. 2000. Degree operators and scope. In Proceedings of the Semantics and Linguistic Theory 10, ed. Brandon Jackson and T. Metthews. CLC Publications, Cornell University, Ithaca. 
Kennedy, Christopher. 1999. Projecting the adjective: The syntax and semantics of gradability and comparison. New York: Garland. (Ph.D. dissertation, University of California, Santa Cruz, 1997)

Ormazabal, Javier. 1995. The syntax of complementation: On the connection between syntactic structure and selection. Doctoral dissertation, University of Connecticut, Storrs.

Sharvit, Yael, and Penka Stateva. 2002. Superlative expressions, context and focus. Linguistics and Philosophy 25: 453-505.

Stateva, Penka. 2000. In defense of the movement theory of superlatives. In Proceedings of the Eastern States Conference on Linguistics 1999, ed. Rebecca Daly and Anastasia Riehl, 215-226. CLC Publications, Cornell University, Ithaca, NY.

Stateva, Penka. 2002. How different are different degree constructions? Doctoral dissertation, University of Connecticut, Storrs. 